\title{
Calcium, Phosphorus and PTH in Patients with End Stage of Chronic Kidney Disease, Undergoing Hemodialysis
}

\author{
Serfa Faja \\ $\mathrm{PhD}$ candidate in medical sciences \\ Amir Shoshi \\ General practitioner at Shkodra Regional Hospital, emergency service General \\ practitioner at the Hemodialysis Center Diavita Shkoder
}

\begin{abstract}
Renal hyperparathyroidism (rHPT) is a common complication of chronic kidney disease characterized by elevated parathyroid hormone levels secondary to derangements in the homeostasis of calcium, phosphate, and vitamin D. Patients with rHPT experience increased rates of cardiovascular problems and bone disease. The Kidney Disease: Improving Global Outcomes guidelines recommend that screening and management of rHPT be initiated for all patients with chronic kidney disease stage 3 (estimated glomerular filtration rate, $<60$ $\mathrm{mL} / \mathrm{min} / 1.73 \mathrm{~m} 2$ ). Since the $1990 \mathrm{~s}$, improving medical management with vitamin $\mathrm{D}$ analogs, phosphate binders, and calcimimetic drugs has expanded the treatment options for patients with rHPT, but some patients still require a parathyroidectomy to mitigate the sequelae of this challenging disease.
\end{abstract}

Keywords: Calcium, Phosphorus and PTH in Patients with End Stage of Chronic Kidney Disease, Undergoing Haemodialysis

\section{Introduction}

Renal hyperparathyroidism (rHPT) is a common complication of CKD characterized by derangements in the homeostasis of calcium, phosphorus, and vitamin D.

rHPT is classically broken into 2 types on the basis of the patient's serum calcium level. Secondary hyperparathyroidism $\left(2^{\circ} \mathrm{HPT}\right)$ is the elevation of parathyroid hormone (PTH) in response to hypocalcemia induced by phosphate retention and reduced calcitriol synthesis as a consequence of reduced renal function ${ }^{1}$. In $2^{\circ} \mathrm{HPT}$, all the parathyroid glands become enlarged owing to parathyroid hyperplasia. Because $2^{\circ} \mathrm{HPT}$ is a compensatory mechanism of the parathyroid glands, it commonly resolves with normalization of calcium and phosphorus homeostasis (eg, renal transplantation). Tertiary hyperparathyroidism $\left(3^{\circ} \mathrm{HPT}\right)$ is seen when a patient with longstanding $2^{\circ} \mathrm{HPT}$ develops autonomous PTH secretion, often associated with hypercalcemia. This is observed in up to $30 \%$ of patients with ESRD, who then undergo renal transplant ${ }^{2} .11$ $3^{\circ} \mathrm{HPT}$ is classically thought to have come from parathyroid hyperplasia, but some studies have suggested that up to $20 \%$ of patients may have single or double adenomas ${ }^{3}$

Since the 1990s, improving medical management with vitamin D analogs, phosphate binders, and calcimimetic drugs has expanded the treatment options for patients with rHPT, but parathyroidectomy remains necessary for many patients.

\section{Normal Calcium and Phosphorus Homeostasis}

\footnotetext{
${ }^{1}$ Martin KJ, Gonzalez EA. Metabolic bone disease in chronic kidney disease. J Am Soc Nephrol. 2007 Mar;18(3):875-85. doi: 10.1681/ASN.2006070771.

${ }^{2}$ Kerby J, Rue LW, Blair H, Hudson S, Sellers MT, Diethelm AG. Operative treatment of tertiary hyperparathyroidism: a single-center experience. Ann Surg. 1998 Jun;227(6):878-86.

${ }^{3}$ Kilgo M, Pirsch J, Warner T, Starling JR. Tertiary hyperparathyroidism after renal transplantation: surgical strategy. Surgery. 1998 Oct;124(4):677-83. discussion 683-4.
} 
Calcium and phosphorus homeostasis is maintained through a complex relationship between the bones, intestine, kidneys, and parathyroid glands. PTH is probably the most important regulator of calcium metabolism and functions primarily via 3 mechanisms:

1. PTH is thought to stimulate PTH receptors mainly on osteoblasts, which then, through multiple cell-to-cell mechanisms, stimulate osteoclast formation and bone resorption, leading to increased serum calcium and phosphorus levels.

2. PTH activates 1-a-hydroxylase in the kidney, which catalyzes the conversion of nonactive 25 -hydroxy $(25-\mathrm{OH})$ vitamin $\mathrm{D}$ to activated 1,25 dihydroxy $(1,25-\mathrm{OH})$ vitamin $\mathrm{D}$. This leads to increased absorption of calcium and phosphorus in the gut.

3. PTH increases reabsorption of calcium and decreases reabsorption of phosphorus in the kidney.

Recently, there has been much interest in the role of fibroblast growth factor 23 (FGF-23), a protein secreted by bone in response to hyperphosphatemia, which functions primarily in maintaining phosphorus homeostasis. FGF-23 stimulates phosphorus excretion in the kidney mainly through reduced action of sodium-phosphate co-transporter in the proximal tubule. It also decreases 1-a-hydroxylase activity, leading to reduced 1,25-OH vitamin D levels.14,15 In CKD, FGF-23 levels progressively rise and are initially thought to be beneficial, given the phosphaturic effects. However, increasing FGF levels are also associated with increased cardiovascular mortality in patients with CKD'.

\section{Pathogenesis}

The pathogenesis of rHPT is complex and incompletely understood (Figure 1).

An increase in PTH levels typically develops when the glomerular filtration rate (GFR) drops below $60 \mathrm{~mL} / \mathrm{min} / 1.73 \mathrm{~m} 2$. Abnormalities in serum levels of phosphorus and calcium tend to occur much later in the course of CKD (typically when the GFR drops below $40 \mathrm{~mL} / \mathrm{min} / 1.73 \mathrm{~m} 2)^{2} .17$ Initially, the elevated PTH levels serve to increase renal phosphorus excretion. However, as the GFR declines further, serum phosphorus levels start to rise and induce hypocalcemia by binding bioavailable calcium as $\mathrm{CaHPO}_{4}$, which indirectly leads to a further rise in PTH production. CKD also leads to decreased activity of 1-a-hydroxylase, thereby decreasing $1,25-\mathrm{OH}$ vitamin $\mathrm{D}$. A lack of $1,25-\mathrm{OH}$ vitamin $\mathrm{D}$ inhibits gastrointestinal absorption of calcium and also directly stimulates the parathyroid glands ${ }^{3}, 4$.

\footnotetext{
${ }^{1}$ Quarles LD. Role of FGF23 in vitamin D and phosphate metabolism: implications in chronic kidney disease. Exp Cell Res. 2012 May 15;318(9):1040-8. doi: 10.1016/j.yexcr.2012.02.027.

${ }^{2}$ Levin A, Bakris GL, Molitch M, et al. Prevalence of abnormal serum vitamin D, PTH, calcium, and phosphorus in patients with chronic kidney disease: results of the study to evaluate early kidney disease. Kidney Int Jan. 2007;71(1):31-8.

${ }^{3}$ Slaiba W, El-Haddad B. Secondary hyperparathyroidism: pathophysiology and treatment. J Am Board Fam Med. 2009 SepOct;22(5):574-81.

${ }^{4}$ Yuen NK, Ananthakrishnan S, Campbell MJ. Hyperparathyroidism of renal disease. Perm J 2016 Summer;20(3):15-127
} 


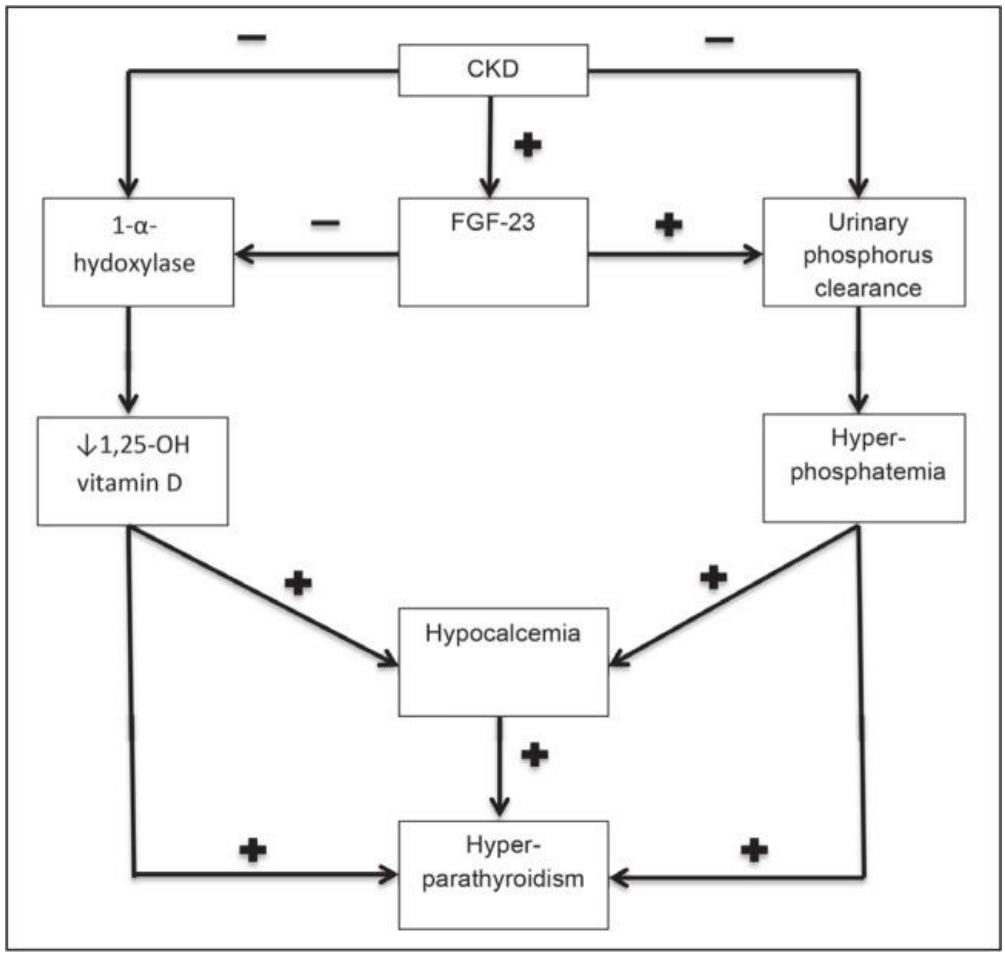

In CKD, chronic stimulation of the parathyroid glands triggers diffuse polyclonal hyperplasia. As the chronic stimulation of CKD continues, the parathyroids begin to develop monoclonal nodules within a background of parathyroid hyperplasia. These nodules demonstrate increased resistance to vitamin $\mathrm{D}$ and calcimimetic medications and may be the etiology of the loss of negative feedback seen in $3^{\circ} \mathrm{HPT}^{1},{ }^{2}$.

\section{Clinical Manifestations}

Renal osteodystrophy refers to a group of bone disorders caused by dysregulation of mineral metabolism in CKD, including osteomalacia, adynamic bone disease, and osteitis fibrosa cystica. Osteomalacia is a state of low bone turnover leading to poor mineralization. Adynamic bone disease is also a low-turnover pathology with normal mineralization that probably results from a low PTH state. The incidence of adynamic bone disease increasing is likely secondary to PTH oversuppression from vitamin $\mathrm{D}$ agents, calcimimetics, and phosphate binders ${ }^{3,4}$. Osteitis fibrosis cystica is a high-turnover bone disease that stems from elevated PTH concentrations stimulating osteoclast activity, bone breakdown, and resorption. This can lead to subsequent bone pain and fractures ${ }^{5}$. With longstanding bone resorption, patients may develop localized regions of bone loss that are then replaced by fibrous tissue, resulting in a brown tumor. These "tumors" appear as welldefined, lytic lesions on radiograph and may be mistaken for metastasis (Figure 2).

\footnotetext{
${ }^{1}$ Madorin C, Owen RP, Fraser WD, et al. The surgical management of renal hyperparathyroidism. Eur Arch Otorhinolaryngol. 2012 Jun;269(6):1565-76. doi: 10.1007/s00405-011-1833-2.

${ }^{2}$ Tominaga Y, Tanaka Y, Sato K, Nagasaka T, Takagi H. Histopathology, pathophysiology, and indications for surgical treatment of renal hyperparathyroidism. Semin Surg Oncol. 1997 Mar-Apr;13(2):78-86.

${ }^{3}$ Slaiba W, El-Haddad B. Secondary hyperparathyroidism: pathophysiology and treatment. J Am Board Fam Med. 2009 Sep-

Oct;22(5):574-81.

${ }^{4}$ Andress DL. Adynamic bone in patients with chronic kidney disease. Kidney Int. 2008 Jun;73(12):1345-54. doi: 10.1038/ki.2008.60.

${ }^{5}$ Pitt S, Sipple R, Chen H. Secondary and tertiary hyperparathyroidism, state of the art surgical management. Surg Clin North Am. 2009 Oct;89(5):1227-39. doi: 10.1016/j.suc.2009.06.011.
} 


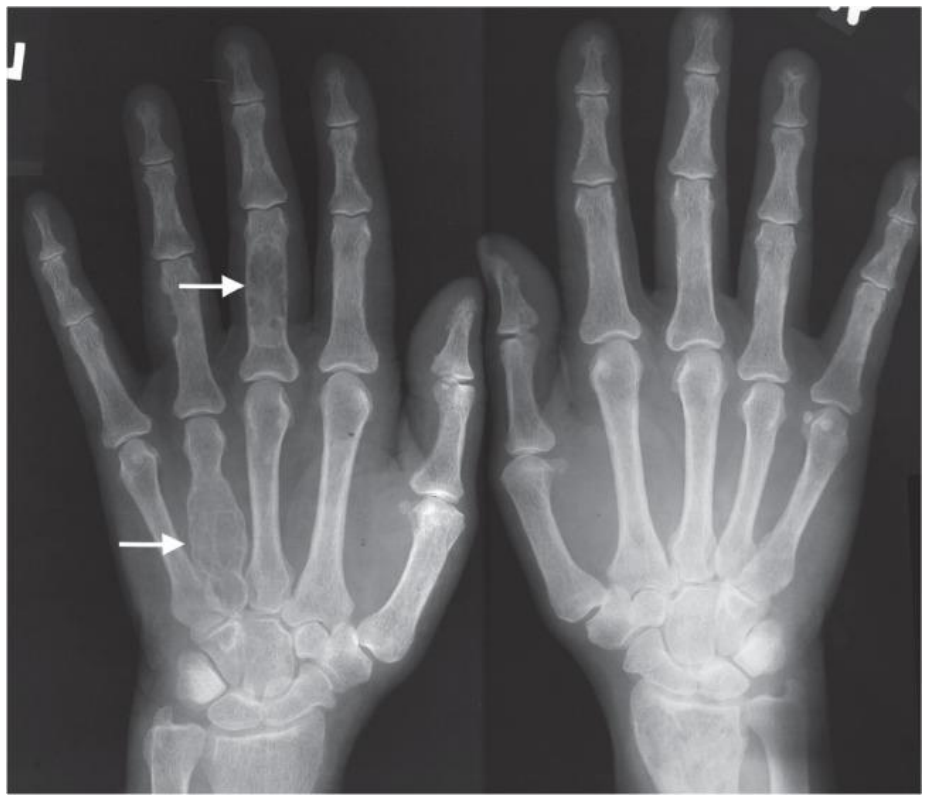

Figure 2.

Radiograph of the hands of a 55-year-old patient with renal osteodystrophy and brown tumors of the fourth metacarpal and third phalanx of the left hand (arrows).

The derangements in calcium and phosphate that result from rHPT may accelerate vascular calcification, including coronary artery calcification. Calcification of the cardiovascular tissue can affect the myocardium, atrial-ventricular conduction, and valvular function ${ }^{12}$. Furthermore, coronary calcification may put patients at an increased risk of cardiovascular events and death $^{3}$. It is difficult to distinguish the unique detrimental effects of rHPT from those of hyperphosphatemia, which is also associated with cardiovascular disease in patients with CKD. Some studies have suggested that FGF-23 may induce arterial smooth muscle myocytes to change into osteoblast-like cells that lead to vascular calcification ${ }^{4}$. Moderate to severe hyperparathyroidism (PTH concentrations $\geq 600 \mathrm{pg} / \mathrm{mL}$ ) may increase risk of cardiovascular death, 7 though the causality of this association is debatable.

There is an association between CKD and medial calcification in the arterioles of the skin and soft tissue leading to vascular compromise and ulceration. This constellation of complications was formerly called calciphylaxis but is now termed calcific uremic arteriolopathy, and it is associated with an eight-fold increase in mortality rate. Tumoral calcinosis is an uncommon complication of longstanding rHPT and is classically associated with high serum levels of calcium and phosphorus. In tumoral calcinosis, the patient can develop soft-tissue calcium deposits that can appear to be soft-tissue malignant tumors on imaging studies

\footnotetext{
${ }^{1}$ Goodman WG. The consequences of uncontrolled secondary hyperparathyroidism and its treatment in chronic kidney disease. Semin Dial. 2004 May-Jun;17(3):209-16.

${ }^{2}$ Yuen NK, Ananthakrishnan S, Campbell MJ. Hyperparathyroidism of renal disease. Perm J 2016 Summer;20(3):15-127

${ }^{3}$ Wilkieson TJ, Rahman MO, Gangji AS, et al. Coronary artery calcification, cardiovascular events, and death: a prospective cohort study of incident patients on hemodialysis. Can J Kidney Health Dis. 2015 Aug 12;2:29. doi: 10.1186/s40697-015-0065-6.

${ }^{4}$ Levin A, Bakris GL, Molitch M, et al. Prevalence of abnormal serum vitamin D, PTH, calcium, and phosphorus in patients with chronic kidney disease: results of the study to evaluate early kidney disease. Kidney Int Jan. 2007;71(1):31-8.
} 


\section{Evaluation of Phospho-Calcic Metabolism}

1. Levels of intact calcium, phosphorus and parathyroid hormone (PTH) should be dosed in all patients with CKD and FG $<60 \mathrm{~mL} / \mathrm{min} / 1.73 \mathrm{~m} 2$. The frequency of these doses should be based on the stage of chronic renal disease. (Table 1).

\begin{tabular}{|l|l|l|l|}
\hline Stage of CKD & GFR $(\mathrm{m} / \mathrm{min} / 1.73 \mathrm{~m} 2)$ & Measurements of PTH & $\begin{array}{l}\text { Measurements od } \\
\text { calcium/phosphorus }\end{array}$ \\
\hline 3 & $30-59$ & Every 12 months & Every 12 months \\
\hline 4 & $15-29$ & Every 3 months & Every 3 months \\
\hline 5 & $<15$ ose dialize & Every month & Every month \\
\hline
\end{tabular}

2. These doses should be performed more frequently if the patient is being treated with concomitant therapy for disorders of plasma calcium, phosphorus or PTH levels.

3. Plasma PTH dosage may be repeated over a longer period of time in those patients with PTH values within the lower limit of target values.

4. The limits of the target values of plasma levels of intact PTH at different stages of CKD are given in Tab.2. Limits of target values of plasma intact PTH according to CKD stages

\begin{tabular}{|l|l|l|}
\hline CKD stages $(\mathrm{pmo} / \mathrm{L}])$ & GFR $(\mathrm{ml} / \mathrm{min} / 1.73 \mathrm{~m} 2)$ & Intact pth RANGE $(\mathrm{pg} / \mathrm{ml})$ \\
\hline 3 & $30-59$ & $35-70[3.85-7.7 \mathrm{pmol} / \mathrm{L}]$ opinion \\
\hline 4 & $15-29$ & $70-110[7.7-12.1 \mathrm{pmo} / \mathrm{L}]$ \\
\hline 5 & $<15$ or hemodialysis & $150-300[16.5-33.0 \mathrm{pmol} / \mathrm{L}]$ evidense \\
\hline
\end{tabular}

\section{Evaluation of Phosphoric Plasmatic Levels'.}

1. In patients with CKD (St. 3 and st.4) plasma phosphorus level should be maintained at or below $2.7 \mathrm{mg} . \mathrm{dL}(0.87 \mathrm{mmol} /$

$\mathrm{L})$ and not more than $4.6 \mathrm{mg} / \mathrm{dL}(1.48 \mathrm{mmol} / \mathrm{L})$

2. In patients with CKD st.5 and in those treated with hemodialysis or peritoneal dialysis, the plasma phosphorus level should be maintained between $3.5-5.5 \mathrm{mg} / \mathrm{dL}(1.13-1.78 \mathrm{mmol} / \mathrm{L})$.

Hyperphosphatemia leads to secondary hyperparathyroidism and elevated levels of PTH through:

a) lowering the levels of ionized calcium;

b) intervention in the production of vit.D;

c) directly affecting the secretion of $\mathrm{PTH}^{2}$.

This process leads to high-turnover bone disease.

Prolonged hyperphosphatemia causes vascular and soft tissue calcifications resulting at least in part from an increase in calcium $x$ phosphorus product ${ }^{3}$ and is associated with an increase in morbidity and mortality ${ }^{4}$. In the case of vascular calcifications, hyperphosphatemia has a direct calcifying effect on the cells of the vascular smooth muscle. Calcification of coronary arteries, cardiac valves and pulmonary tissue causes cardiac disease, the leading cause of death in patients with CKD. It is therefore very important to prevent hyperphosphatemia and to maintain phosphorus levels within normal limits.

Among the factors contributing to secondary hyperparathyroidism in patients with CKD are phosphorus retention and / or elevated plasma phosphorus levels.

\footnotetext{
${ }^{1}$ Guidelines for mineralococcal abnormalities in CKD, Albanian group authors

${ }^{2}$ Naveh-Many T, Rahamimov R, Livni N, Silver J:Parathyroid cell proliferation in normal and chronic renal failure rats. The effects of calcium, phosphate, and vitamin D. J Clin Invest 96:1786-1793, 1995

${ }^{3}$ Combe C, Aparicio M: Phosphorus and protein restriction and parathyroid function in chronic renal failure. Kidney Int 46:1381-1386, 1994

${ }^{4}$ Marchais SJ, Metivier F, Guerin AP, London GM: Association of hyperphosphataemia with haemodynamic disturbances in end-stage renal disease. Nephrol Dial Transplant 14:2178-2183, 1999
} 
To prevent morbidity and mortality, it is recommended that plasma phosphorus levels should be maintained between 2.7$4.6 \mathrm{mg} / \mathrm{dl}(0.87-1.49 \mathrm{mmol} / \mathrm{L})$ in patients with CKD st.3 and 4, and between 3.5-5.5 mg / dl $(1.13-1.78 \mathrm{mmol} / \mathrm{L})$ in patients with CKD st.5

\section{Plasma Calcium and Calcium-Fosfor Product ${ }^{1}$}

In patients with CKD stage 3 and 4 :

Plasma levels of corrected total calcium should be kept within the values of the laboratory rate used In patients with CKD stage 5:

Plasma levels of corrected total calcium should be kept within the laboratory norm values used, preferably within the minimum limit (8.4-9.5 mg / dL [2.10-2.37 mmol /L]).

In cases where the plasma level of corrected total calcium exceeds $10.2 \mathrm{mg} / \mathrm{dL}(2.54 \mathrm{mmol} / \mathrm{L})$, the medications that cause the increase in calcium should be modified as follows.

a. Patients receiving calcium-based phosphorus binders, the dose should be reduced, or switched to a calcium-based, noncalcium-based phosphorus binder aluminum, not magnesium based.

b. In patients receiving active vitamin $\mathrm{D}$, we should reduce its dose, or discontinue therapy until plasma levels of total calcium are corrected within the target range $(8.4-9.5 \mathrm{mg} / \mathrm{dL}[2.10-2.37 \mathrm{mmol} / \mathrm{L}])$.

c. If hypercalcemia (plasma levels of total corrected calcium> $10.2 \mathrm{mg} / \mathrm{dL}$ [2.54 mmol / L]) persists despite modification of vitamin $\mathrm{D}$ therapy and / or disruption of calcium-based phosphorus binders, low-concentration dialysis may be used. of calcium in dialysate fluid (1.5-2 mEq / L) for 3-4 weeks.

\section{In patients with CKD st. 3-5:}

1. The total dose of calcium taken (including that obtained with the diet and that obtained with calcium-based phosphorus binders) shall not exceed $2000 \mathrm{mg} /$ day.

2. The calcium-phosphorus product must be kept $<55 \mathrm{mg} 2$ / dL2. This is best achieved by controlling the plasma levels of phosphorus within the range of target values.

3. Patients whose plasma total calcium levels are below the minimum values of the laboratory values used $(<8.4 \mathrm{mg} / \mathrm{dL}$ [2.10 mmol / L]) should receive plasma calcium therapy if:

a. Have clinical symptoms of hypocalcemia such as paresthesia, Chvostek-Trousseau syndrome, bronchospasm, laryngospasm, tetany, and / or convulsive crisis;

b. The plasma level of intact PTH is below the target values for the CKD stage

4. Treatment for hypocalcemia should include calcium salts such as calcium carbonate and / or vitamin D oral.

The total dose of calcium taken in patients with CKD should not exceed $2000 \mathrm{mg} /$ day. In these patients the fraction of calcium absorbed in the duodenum and jejunum is reduced because this process depends on the year. D, and in CKD this vitamin is lowered. However, passive calcium uptake, which depends on the gradient, may increase if we increase the dose of calcium obtained.

Patients with CKD who have been treated with vit $D$ or calcium supplements tend to develop hypercalcemia, especially in those with adenamic bone disease.

Hypercalcemia, together with hyperphosphatemia, or each individually may be responsible for increased Ca-P product. Since plasma phosphorus levels in patients with CKD are usually increased by a larger factor (from $3.5 \mathrm{mg} / \mathrm{dl}[1.13 \mathrm{mmol} /$ L] to $7 \mathrm{mg} \mathrm{/} \mathrm{dl} \mathrm{[2.26mmol} \mathrm{/} \mathrm{L]} \mathrm{giving} \mathrm{a} \mathrm{factor} \mathrm{of} \mathrm{2),} \mathrm{compared} \mathrm{to} \mathrm{calcium} \mathrm{(from} 9.5 \mathrm{mg} / \mathrm{dl}$ [2.37 mmol / L] to $11 \mathrm{mg} / \mathrm{dl}[2.74$ $\mathrm{mmol} / \mathrm{L}$ ], giving a factor of 1.2), the relative importance of plasma phosphorus levels in the delivery of a high Ca $\mathrm{P}$

\footnotetext{
${ }^{1}$ Guidelines for mineralococcal abnormalities in CKD, Albanian group authors
} 
product, is given as $\mathrm{mg} 2$ / $\mathrm{dL} 2$, it is greater than plasma calcium levels. Also, plasma calcium levels can be critical ${ }^{1}$ if plasma phosphorus levels are too high, as is the case of patients with CKD st.5.

In the presence of a high $\mathrm{Ca} \times \mathrm{P}$ product in the blood, soft tissue calcifications are common but the latter are not always associated with high $\mathrm{Ca} \times \mathrm{P}$, since many factors are involved in the genesis of these calcifications.

It is important that patients with CKD have normal values of corrected total calcium, as it is known that chronic hypocalcemia causes secondary hyperparathyroidism, has adverse effects on bone mineralization and may be associated with increased mortality.

Caution should also be exercised in the dose of calcium taken because it can be switched to hypercalcaemia. Spontaneous hypercalcemia can occur in patients with CKD.

The total calcium level should be adjusted based on the level of albumin through the formula:

Corrected calcium $(\mathrm{mg} / \mathrm{dl})=$ total calcium $(\mathrm{mg} / \mathrm{dl})+0.0704 \times$ [34-plasma albumin $(\mathrm{g} / \mathrm{L})$ ]

A simpler formula is used for routine clinical interpretation of plasma calcium:

Corrected total calcium $(\mathrm{mg} / \mathrm{dl})=$ total calcium $(\mathrm{mg} / \mathrm{dl})+0.8 \times$ [4-plasma albumin $(\mathrm{g} / \mathrm{dl})$ ]

Patients with FG $<60 \mathrm{ml} / \mathrm{min} / 1.73 \mathrm{~m} 2$ (CKD st.3) usually, but not always, have significant decreases in plasma levels of total and free calcium. Plasma calcium levels decline further with impaired renal function.

In advanced CKD, the total calcium fraction associated with complex compounds increases; therefore the free calcium fraction decreases, despite the level of total calcium being normal. Acidosis on the other hand can increase the level of free calcium. When hemodialysis begins, plasma calcium levels normalize. It should be borne in mind that dialysis does not play a role in improving calcium absorption.

It is recommended that the daily dose of calcium intake in CKD st. 3 be $1.5-2 \mathrm{~g} /$ day and in st. 4 and 5 (patients not on dialysis), to be 1.5-1.8 $\mathrm{g} /$ day.

Calcium supplements should be started in patients with CKD st.2 when PTH begins to increase, $\mathrm{FG}<60 \mathrm{ml} / \mathrm{min} /$ $1.73 \mathrm{~m} 2$

An association between high $\mathrm{Ca} \times \mathrm{P}$ product and death risk was observed, so for every 10 -fold increase, an $11 \%$ increase in relative risk of death was observed.

If the product $\mathrm{Ca} \times \mathrm{P}$ exceeds 55 , then the risk of developing calculations increases and survival decreases. Therefore the target level of the product Ca $\mathrm{P}$ s should be $<55$.

\section{Low Phosphorus Diet}

A low phosphorus diet is recommended for patients with CKD and $2^{\circ} \mathrm{HPT}$ with hyperphosphatemia ${ }^{2}$. Dietary restriction of phosphorus in patients without elevated levels of phosphorus, but with elevated PTH levels only, is controversial. Unfortunately, this is very difficult given the high prevalence of phosphorus in Western diets. Dietary phosphorus comes from 2 sources: 1) protein-rich food groups such as meat and milk; and 2) phosphorus additives, which are used to process meats and cheeses. Phosphorus used as an additive is often only implied in the ingredients list, and not individually reported on the food label. Therefore, the true amount of phosphorus contained in a product may be underestimated.14 Patient education regarding this distinction may help them avoid phosphorous-rich foods.

\footnotetext{
${ }^{1}$ Fernandez E, Montoliu J: Successful treatment of massive uraemic tumoral calcinosis with daily haemodialysis and very low calcium dialysate. Nephrol Dial Transplant 9:1207-1209, 1994

${ }^{2}$ Kidney Disease: Improving Global Outcomes (KDIGO) CKD-MBD Work Group KDIGO clinical practice guideline for the diagnosis, evaluation, prevention, and treatment of chronic kidney disease-mineral and bone disorder (CKD-MBD) Kidney Int Suppl. 2009

Aug;76(113):S1-130. doi: 10.1038/ki.2009.188
} 


\section{Phosphate Binders}

Because of the difficulty in maintaining a low phosphorus diet, phosphate binders are usually an essential part of medical therapy for patients with CKD. Phosphate binders have been shown to decrease serum phosphorous and PTH levels.

Several phosphate binders are available, including aluminum hydroxide, calcium salts, sevelamer hydrochloride, sevelamer carbonate, and lanthanum carbonate. In general, aluminum hydroxide should be limited to a short period because of the risk of aluminum toxicity. Newer agents such as lanthanum have unknown long-term effects of bone deposition. Iron-based binders such as sucroferric oxyhydroxide are also available to lower serum phosphorous. The Kidney Disease Outcomes Quality Initiative recommends for patients with CKD stages 3 and 4, that phosphate binders be used if phosphorus levels cannot be controlled within the target range despite dietary phosphorus restriction. In patients who remain hyperphosphatemic despite initiation of a single phosphate binder, combination therapy can be used ${ }^{1}$. It is interesting to note that lanthanum, being a heavy metal, commonly shows up as radiopaque in noncontrast radiologic studies of the gastrointestinal tract. 30

\section{Vitamin D Analogs}

As described above, 1,25-OH vitamin D deficiency is a major mechanism of rHPT, and vitamin D replacement has been shown to effectively suppress PTH secretion ${ }^{2}$.Several forms of vitamin D are available, including ergocalciferol (which requires activation in the kidney to $1,25-\mathrm{OH}$ vitamin $\mathrm{D}$ ), as well as activated forms such as calcitriol, paricalcitol, and doxercalciferol. Although observational studies have suggested improved survival in patients treated with vitamin $D$ analogs, a 2007 meta-analysis showed no difference in mortality, bone pain, vascular disease, or rate of parathyroidectomy when comparing patients on vitamin $\mathrm{D}$ analogs versus those not taking vitamin $\mathrm{D}$.

The Kidney Disease: Improving Global Outcomes work group recommends that in patients with CKD stages 3 to 5 (not on dialysis), attempts to control hyperphosphatemia, hypocalcemia, and vitamin D deficiency be made first. If PTH remains elevated or is progressively rising, treatment with calcitriol or vitamin $D$ analogs is suggested. Close attention must be paid to serum levels of calcium and phosphorus, which if greater than $10.2 \mathrm{mg} / \mathrm{dL}$ and $4.6 \mathrm{mg} / \mathrm{dL}$, respectively, may warrant modification in therapy. In patients with CKD stage 5 on dialysis, active vitamin D sterols (such as calcitriol, paricalcitol, or doxercalciferol) are used to control hyperparathyroidism.

\section{Calcimimetics}

Cinacalcet $\mathrm{HCL}$ is a calcimimetic agent that exhibits allosteric modulation of the calcium receptor on the parathyroid gland, increasing sensitivity to extracellular calcium and thereby suppressing PTH secretion.36 The effectiveness of cinacalcet in lowering PTH concentrations in ESRD patients has been demonstrated in multiple studies. Combined analysis of these studies showed that cinacalcet decreases rates of parathyroidectomy, fractures, and cardiovascular hospitalization. Patients receiving cinacalcet treatment rather than placebo also have improvements in self-reported physical function and less bodily pain. ${ }^{3}$

In 2012, the Evaluation of Cinacalcet Hydrochloride Therapy to Lower Cardiovascular Events Trial randomized patients with ESRD and moderate to severe rHPT to cinacalcet or placebo and found that cinacalcet did not significantly reduce overall or cardiovascular mortality ${ }^{4}$. A recent Cochrane review corroborated these findings but did find that patients taking cinacalcet had a significant increase in the rate of nausea, vomiting, and hypocalcemia, suggesting that the potential risks associated with cinacalcet use in ESRD patients may outweigh the benefits. These clinical uncertainties further bring into question the costs of cinacalcet treatment. Currently the US spends $\$ 260$ million annually on cinacalcet, accounting for the largest single drug cost in dialysis patients. Despite maximal medical interventions, surgical parathyroidectomy is still required for many patients. 41

\footnotetext{
${ }^{1}$ Goodman WG. The consequences of uncontrolled secondary hyperparathyroidism and its treatment in chronic kidney disease. Semin Dial. 2004 May-Jun;17(3):209-16.

${ }^{2}$ Costa AF, dos Reis LM, Ribeiro MC, Moysés RM, Jorgetti V. Effects of calcitriol on parathyroid function and on bone remodeling in secondary hyperparathyroidism. Nephrol Dial Transplant. 2003 Apr;18(4):743-49.

${ }^{3}$ Block GA, Martin KJ, De Francisco AL, et al. Cinacalcet for secondary hyperparathyroidism in patients receiving hemodialysis. N Engl J Med. 2004 Apr 8;350(15):1516-25.

${ }^{4}$ EVOLVE Trial Inestigators. Chertow GM, Block GA, Correa-Rotter R, et al. Effect of cinacalcet on cardiovascular disease in patients undergoing dialysis. N Engl J Med. 2012 Dec 27;367(26):2482-94. doi: 10.1056/NEJMoa1205624.
} 


\section{Indications for Surgical Treatment}

As stated in the Clinical Practice Guidelines for Bone Metabolism and Disease in Chronic Kidney Disease, published in 2003 by the Kidney Disease Outcomes Quality Initiative, the indications for parathyroidectomy are not well defined. Highquality studies are currently lacking to evaluate which patients might benefit from parathyroidectomy. In lieu of such data, the National Kidney Foundation recommends that the criteria in the Sidebar: Indications for Consideration for Parathyroidectomy be used to merit referral to an experienced surgeon for evaluation 1 .

\begin{tabular}{l}
\hline Indications for Consideration for Parathyroidectomy \\
Medical management of rHPT $>6$ months with \\
Hypercalcemia or hyperphosphatemia \\
\hline PTH $>800 \mathrm{pg} / \mathrm{mL}$ \\
\hline Calciphylaxis with documented elevated PTH levels \\
\hline Osteoporosis (T-score $>2.5$ SD below mean), pathologic bone fracture \\
\hline Symptoms/signs \\
\hline Pruritus \\
\hline Bone pain \\
\hline Severe vascular calcifications \\
\hline Myopathy
\end{tabular}

PTH = parathyroid hormone; $r \mathrm{rPT}=$ renal hyperparathyroidism, $\mathrm{SD}=$ standard deviation

\section{Statistical data}

Total number of patient in May 2018

$\begin{array}{ll}\text { Patient suffering from hypocalcemia } & 37\end{array}$

$\begin{array}{ll}\text { Patient suffering from hyperphosphatemia } & 17\end{array}$

$\begin{array}{lr}\text { Patient with hyperparathyroidism } & 27\end{array}$

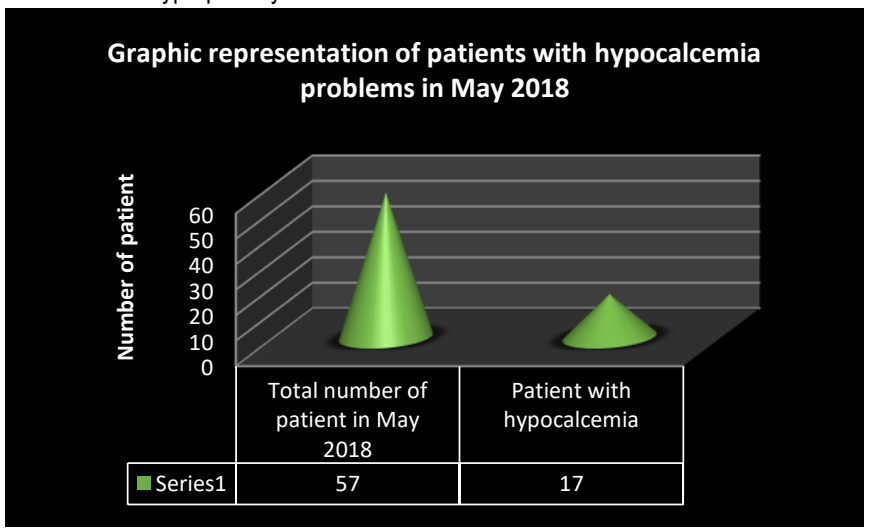

\footnotetext{
${ }^{1}$ National Kidney Foundation K/DOQI clinical practice guidelines for bone metabolism and disease in chronic kidney disease. Am J Kidney Dis. 2003 Oct;42(4 Suppl 3):S1-201.
} 


\section{Graphic representation of patients who have problems with hyperphosphatemia in May 2018}

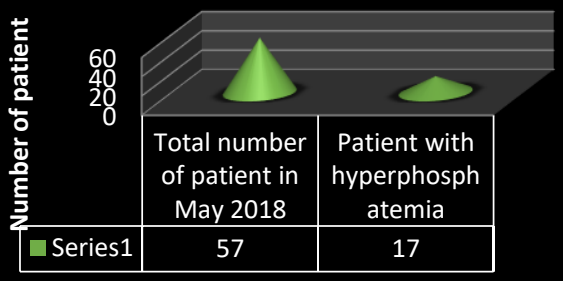

\section{Graphic representation of patients with hyperparathyroidism problems in May 2018}

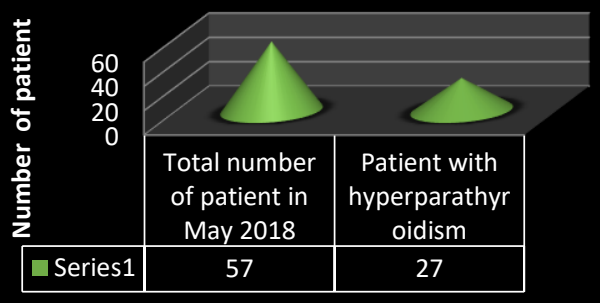

Total number of patient in November 2018

Patient with hypocalcemia

Graphic representation of patients with hypocalcemia problems in November 2018

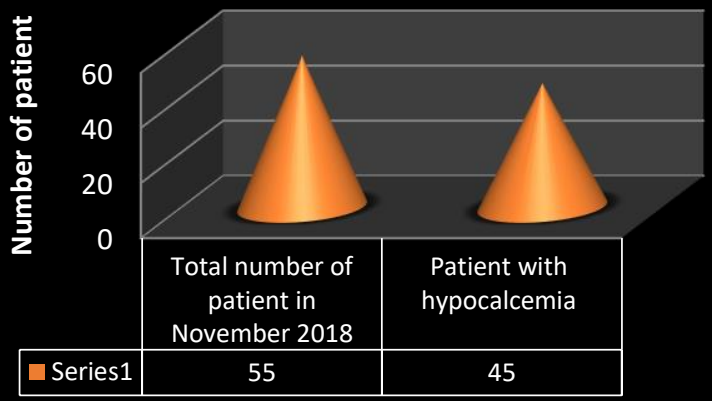



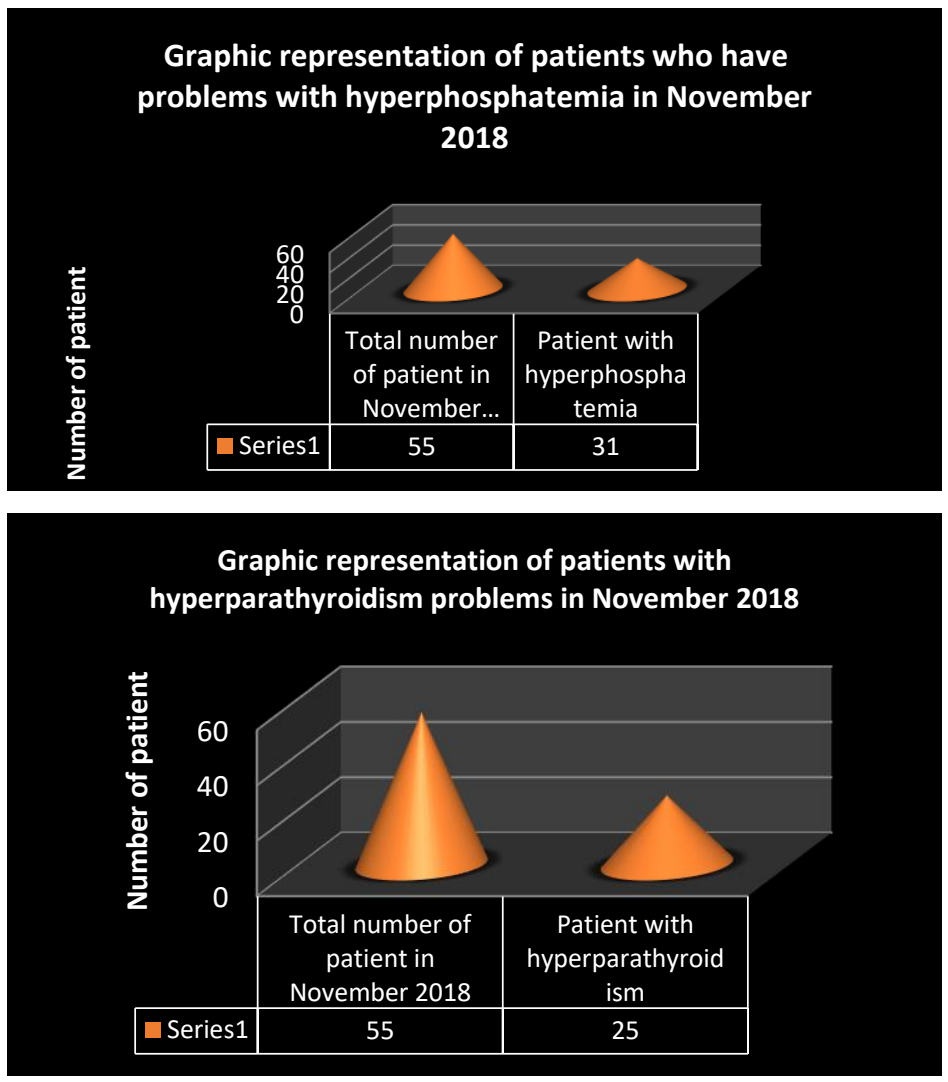

Total number of patient in May 2018

Patients suffering from hyperparathyroidism, hypocalcemia and hyperphosphatemia in May 2018

9

\section{Graphic presentation of patients suffering from \\ hyperparathyroidism, hypocalcemia and hyperphosphatemia in May 2018}

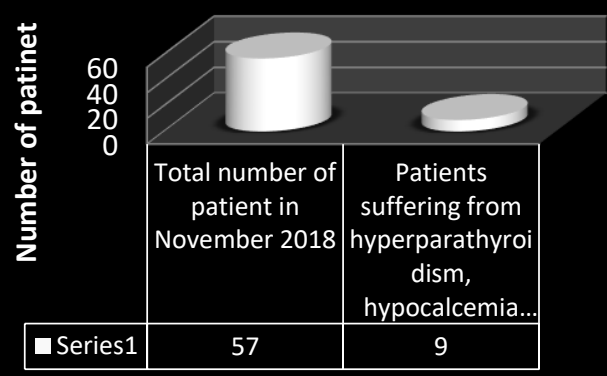




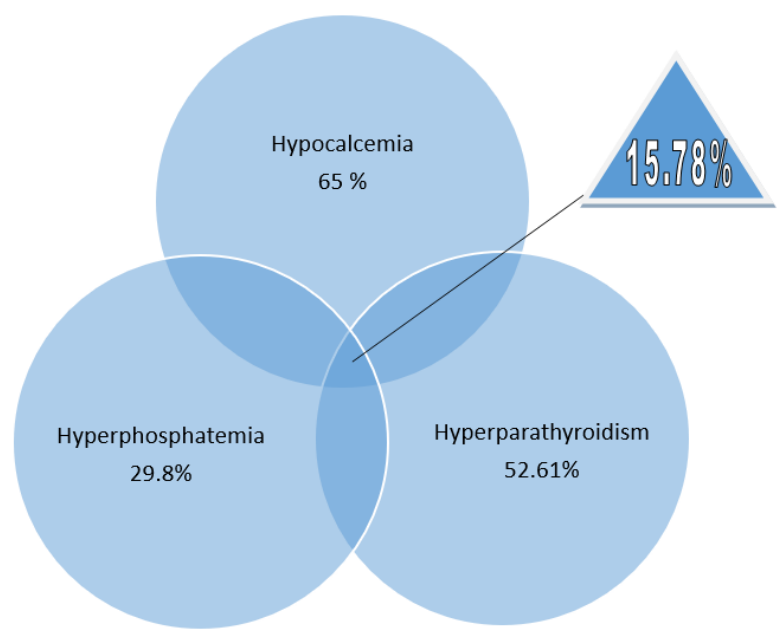

\section{Diagram 1}

Presents the percentage of patients suffering from renal hyperparathyroidism, hypocalcemia and hyperphosphatemia for the first 6 months of 2018

\begin{tabular}{|l|l|}
\hline Total number of patient in November 2018 & 55 \\
\hline $\begin{array}{l}\text { Patients suffering from hyperparathyroidism, } \\
\text { hypocalcemia and hyperphosphatemia in November } 2018\end{array}$ & 18 \\
\hline
\end{tabular}

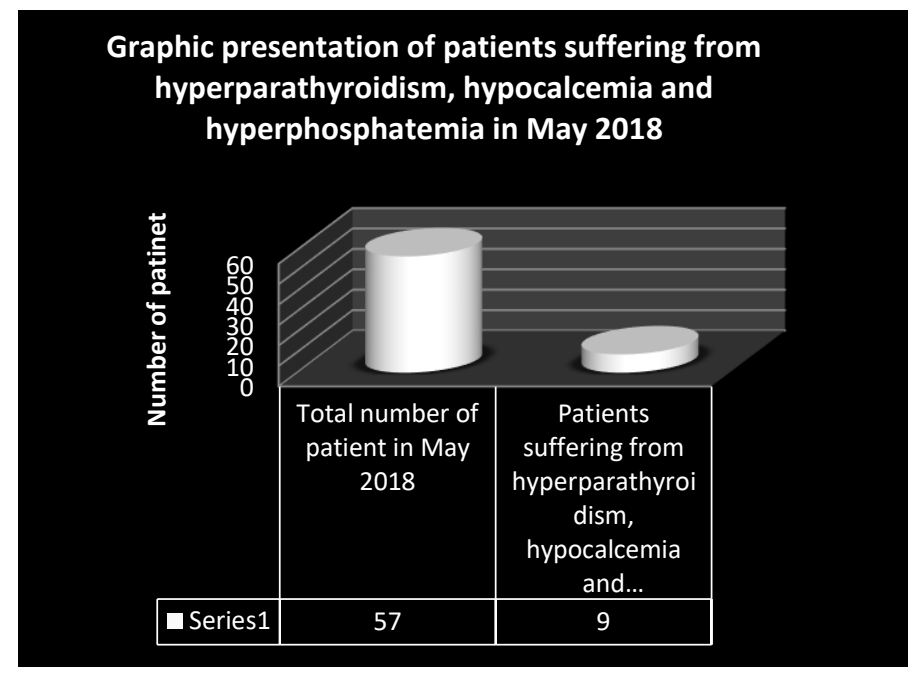



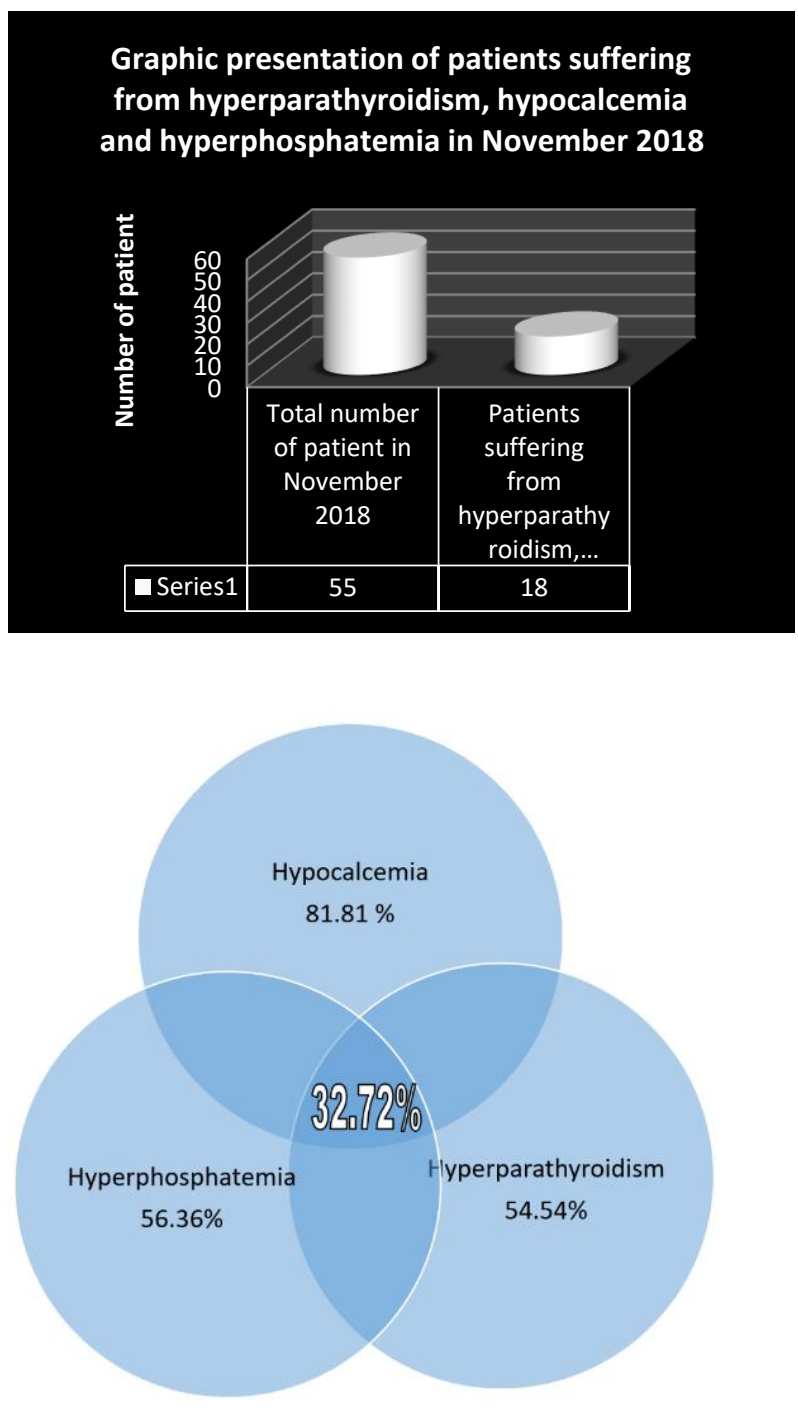

\section{Diagram 2}

Presents the percentage of patients suffering from renal hyperparathyroidism, hypocalcemia and hyperphosphatemia for the second half of 2018

\section{Conclusions}

It is difficult and multidisciplinary to treat these patients and prevent complications.

The best way to treat this is to begin with the awareness of the patient who, in the early stages of chronic renal disease, should maintain a strict dietary schedule and strictly follow the recommendations given by the physician.

Prevention of these complications should also be done by the physician who should closely follow the patient by recommending examinations according to world guidelines, the results of the examinations should be accompanied by appropriate therapy. 
It is worth noting that the therapy for these patients is costly and unfortunately the patients in our country are not reimbursed for all the necessary medications, as a consequence the patients fail to be properly treated leading to an acceleration of renal hyperparathyroidism.

Our study shows that the majority of patients, respectively, $54.38 \%$ have hyperparathyroidism above target values for the first 6 months of 2018 and $54.54 \%$ have hyperparathyroidism values higher than the target values for the second half of 2018 .

With hypocalcemia there are about $63.15 \%$ of patients in the first 6 months of 2018 and about $81.8 \%$ in the second half of 2018.

With hyperphosphatemia are about $29.82 \%$ of patients for the first 6 months and $56.36 \%$ for the second 6 months of 2018 .

From reviewing the above data in the two six months of 2018 we have an increase in the number of patients who have undergone hypocalcemia, hyperphosphatemia and hyperparathyroidism, a growth which is very significant as it results in almost doubling the number of patients.

Although detailed examinations are being conducted and patients are recommended strict diet and regular medication therapy it is noted that we have not achieved this goal as patients need to be more understandable and respect the doctor's advice and increase the role of the state in reimbursement. of drugs for these patients.

\section{References}

[1] Martin KJ, Gonzalez EA. Metabolic bone disease in chronic kidney disease. J Am Soc Nephrol. 2007 Mar;18(3):875-85. doi: 10.1681/ASN.2006070771.

[2] Kerby J, Rue LW, Blair H, Hudson S, Sellers MT, Diethelm AG. Operative treatment of tertiary hyperparathyroidism: a single-center experience. Ann Surg. 1998 Jun;227(6):878-86.

[3] Kilgo M, Pirsch J, Warner T, Starling JR. Tertiary hyperparathyroidism after renal transplantation: surgical strategy. Surgery. 1998 Oct;124(4):677-83. discussion 683-4.

[4] Quarles LD. Role of FGF23 in vitamin D and phosphate metabolism: implications in chronic kidney disease. Exp Cell Res. 2012 May 15;318(9):1040-8. doi: 10.1016/j.yexcr.2012.02.027.

[5] Levin A, Bakris GL, Molitch M, et al. Prevalence of abnormal serum vitamin D, PTH, calcium, and phosphorus in patients with chronic kidney disease: results of the study to evaluate early kidney disease. Kidney Int Jan. 2007;71(1):31-8.

[6] Slaiba W, El-Haddad B. Secondary hyperparathyroidism: pathophysiology and treatment. J Am Board Fam Med. 2009 Sep-Oct;22(5):574-81.

[7] Madorin C, Owen RP, Fraser WD, et al. The surgical management of renal hyperparathyroidism. Eur Arch Otorhinolaryngol. 2012 Jun;269(6):1565-76. doi: 10.1007/s00405-011-1833-2.

[8] Tominaga Y, Tanaka Y, Sato K, Nagasaka T, Takagi H. Histopathology, pathophysiology, and indications for surgical treatment of renal hyperparathyroidism. Semin Surg Oncol. 1997 Mar-Apr;13(2):78-86.

[9] Slaiba W, El-Haddad B. Secondary hyperparathyroidism: pathophysiology and treatment. J Am Board Fam Med. 2009 Sep-Oct;22(5):574-81.

[10] Andress DL. Adynamic bone in patients with chronic kidney disease. Kidney Int. 2008 Jun;73(12):1345-54. doi: 10.1038/ki.2008.60. .

[11] Pitt S, Sipple R, Chen H. Secondary and tertiary hyperparathyroidism, state of the art surgical management. Surg Clin North Am. 2009 Oct;89(5):1227-39. doi: 10.1016/j.suc.2009.06.011.

[12] Goodman WG. The consequences of uncontrolled secondary hyperparathyroidism and its treatment in chronic kidney disease. Semin Dial. 2004 May-Jun;17(3):209-16.

[13] Yuen NK, Ananthakrishnan S, Campbell MJ. Hyperparathyroidism of renal disease. Perm J 2016 Summer;20(3):15-127 
[14] Wilkieson TJ, Rahman MO, Gangji AS, et al. Coronary artery calcification, cardiovascular events, and death: a prospective cohort study of incident patients on hemodialysis. Can J Kidney Health Dis. 2015 Aug 12;2:29. doi: 10.1186/s40697-015-0065-6. .

[15] Levin A, Bakris GL, Molitch M, et al. Prevalence of abnormal serum vitamin D, PTH, calcium, and phosphorus in patients with chronic kidney disease: results of the study to evaluate early kidney disease. Kidney Int Jan. 2007;71(1):31-8.

[16] Fq13, udhezues për anomalite mineralokockore nga SRK, grupautoresh

[17] Naveh-Many T, Rahamimov R, Livni N, Silver J:Parathyroid cell proliferation in normal and chronic renal failure rats. The effects of calcium, phosphate, and vitamin D. J Clin Invest 96:1786-1793, 1995

[18] Combe C, Aparicio M: Phosphorus and protein restriction and parathyroid function in chronic renal failure. Kidney Int 46:1381-1386, 1994

[19] Marchais SJ, Metivier F, Guerin AP, London GM: Association of hyperphosphataemia with haemodynamic disturbances in end-stage renal disease. Nephrol Dial Transplant 14:2178-2183, 1999

[20] Fernandez E, Montoliu J: Successful treatment of massive uraemic tumoral calcinosis with daily haemodialysis and very loë calcium dialysate. Nephrol Dial Transplant 9:1207-1209, 1994

[21] Kidney Disease: Improving Global Outcomes (KDIGO) CKD-MBD Work Group KDIGO clinical practice guideline for the diagnosis, evaluation, prevention, and treatment of chronic kidney disease-mineral and bone disorder (CKD-MBD) Kidney Int Suppl. 2009 Aug;76(113):S1-130. doi: 10.1038/ki.2009.188

[22] Goodman WG. The consequences of uncontrolled secondary hyperparathyroidism and its treatment in chronic kidney disease. Semin Dial. 2004 May-Jun;17(3):209-16.

[23] Costa AF, dos Reis LM, Ribeiro MC, Moysés RM, Jorgetti V. Effects of calcitriol on parathyroid function and on bone remodeling in secondary hyperparathyroidism. Nephrol Dial Transplant. 2003 Apr;18(4):743-49.

[24] Block GA, Martin KJ, De Francisco AL, et al. Cinacalcet for secondary hyperparathyroidism in patients receiving hemodialysis. N Engl J Med. 2004 Apr 8;350(15):1516-25.

[25] National Kidney Foundation K/DOQI clinical practice guidelines for bone metabolism and disease in chronic kidney disease. Am J Kidney Dis. 2003 Oct;42(4 Suppl 3):S1-201. 